ISSN: $2594-4827$

\title{
REFLEXÕES SOBRE O ATO DE EDUCAR EM TEMPOS DIFÍCEIS ${ }^{1}$
}

Marcelo Seráfico

Antes de mais nada gostaria de agradecer aos colegas do IFAM e particularmente ao Elder, pela oportunidade de estar aqui dividindo com vocês algumas reflexões sobre o "mundo do trabalho contemporâneo" e o lugar dos educadores nele.

Sinto-me também privilegiado de poder dividir a exposição com Jocélia e Eurico, pessoas pelas quais nutro além de respeito, afeto, e com as quais compartilho ideais de sociedade.

O mundo do trabalho, em geral, e o mundo do trabalho do educador, em específico, andam desafiados por um conjunto de ideias que são, mais que tudo, sintomáticas da emergência de graves problemas para os quais não se tem adequadas soluções.

Essas ideias envolvem, impactam, afetam, portanto, o ato de educar. Sim, pois educar, como ler, é um ato através do qual, simultaneamente, participamos e nos apropriamos do mundo a partir da relação com o outro; a partir de uma relação cujo propósito é fazer brotar das subjetividades os conteúdos objetivos da realidade social que as constituiu, seja como forma de esclarecimento seja como forma de provocação da inteligência.

E me parece inegável, hoje, que nossas subjetividades e relações pedagógicas estejam atravessadas por ideias como as de empreendedorismo, empregabilidade e carreira, para ficar em três das fundamentais. E todas elas nascem e se afirmam como respostas aos problemas desencadeados pelo desemprego estrutural característico do capitalismo contemporâneo.

Nesse diálogo, pretendo, portanto, (a) caracterizar o desemprego estrutural, (b) indicar o significado específico daquelas três noções, (c) mostrar como elas promovem o que, por analogia, poderíamos chamar de ajustamento estrutural-ideológico do discurso político sobre o trabalho e (d) o por que ele, o discurso e o que dele resulta como ação, dificilmente são e serão suficientes para resolver o problema do desperdício de força de trabalho.

\footnotetext{
${ }^{1}$ Apresentação feita na ocasião de uma mesa redonda no IFAM-Manaus, no dia 29 de novembro de 2018, no Simpósio Amazônico em Educação Profissional e Tecnológica (SAEPT).
} 
Faço essa reflexão tendo em vista uma condição muito particular do trabalho do educador, qual seja, a de que somos formados e formamos pessoas com o intuito de, mais ou menos, prepara-las para o mundo. Isto é, espera-se de nós que contribuamos para que pessoas sejam expostas e aprendam conteúdos disciplinares que, juntos e misturados, as converterão em trabalhadores e cidadãos competentes e habilidosos.

Portanto, o trabalho docente, ainda hoje, se reveste de uma dupla função: a de formar indivíduos para a sociedade e a de fazê-los refletir sobre a sociedade na e para a qual estão sendo formados, buscando mantê-la e/ou transformá-la, a depender.

Mas que sociedade é essa? Qual a formação adequada para os indivíduos? Afinal, educação para quê?

Da resposta a essa pergunta dependem outras relacionadas a o que ensinar-aprender, como fazê-lo e onde fazê-lo. Na verdade, trata-se de uma discussão que se relaciona a interpretações da realidade, visões de mundo e projetos de sociedade.

Nas instituições de ensino superior estamos acostumados a educar para uma profissão. Formamos profissionais - bacharéis, licenciados e tecnólogos - habilitados a desempenhar funções demandadas por instituições públicas e privadas as mais variadas. Aqueles que chegam ao ensino superior passaram antes por cerca de 12 anos de estudos em escolas, lugares nos quais tomaram contato com conteúdos curriculares cuja função mais específica, pode-se dizer, é ao mesmo tempo a de formá-los para participar da vida civil da nação, isto é, torna-los cidadãos, e dotá-los de conhecimentos que os habilitem a ingressar no ensino superior.

Em boa medida, nosso ensino médio é um preparatório para o mundo da concorrência profissionalizada. O centro dos ensinamentos e da aprendizagem é preparar os jovens para a realização de provas, para a participação em processos seletivos que, bemsucedidos, os levarão a uma profissão. A esperança, aposta ou ilusão é que "profissionalizados", esses jovens terão desenvolvido suas habilidades e competências individuais ao ponto de se tornarem mais competitivos e aptos ou ao emprego ou a “empreender".

De imediato, surgem novos questionamentos: o que é uma boa formação? O que é o mercado de trabalho? Uma boa formação, por si só, habilita a inserção do indivíduo no 
mercado de trabalho? Existe diferença entre uma boa formação acadêmica e uma formação para o mercado de trabalho?

Enfim, se coloca no centro do debate o papel da educação superior, a relação da educação com a economia e a possibilidade de, através da educação, o jovem realizar suas aspirações de vida.

Mas isso nos coloca diante do desafio de definir, hoje, o que é uma profissão, o que é o mercado de trabalho e em que medida a inserção nele pode assegurar uma vida plena.

Se assim for, não devemos nos enganar: vivemos um momento de nossa história em que estão em causa o papel da educação e do educador; em que está em causa o próprio papel e alcance da educação vista como processo formal de reprodução da sociedade, sim, mas também como processo de socialização.

Apresentando assim o problema, proponho que não pensemos na "atividade docente" mas sim no "trabalho do educador". Por que?

A palavra docente vem do latim docens, e indica aquele que ensina, instrui e informa. ${ }^{2}$ Educação, palavra originada de educare, também do latim, tem a acepção primitiva de "levar, conduzir, guiar" (idem). Interpretando as raízes etimológicas desse vocábulo, Martins sugere que "significa 'trazer à luz a ideia` ou filosoficamente fazer a criança passar da potência ao ato, da virtualidade à realidade".

Há entre o docere e o educare uma diferença substantiva: a diferença entre "ensinar e levar", entre "instruir e conduzir", entre "informar e guiar". De modo sintético e para não nos demorarmos muito mais nessa preliminar, eu diria que a o ensinar está contido no educar, logo é parte de um todo maior que implica um movimento da razão promovido coletivamente com o intuito de, esclarecendo a realidade, torna-la objeto da ação, isto é, da conversão da potência do saber em ato do saber.

Parece-me que nossas atividades são atividades de educadores e não apenas de docentes. Não nos dedicamos apenas a ensinar. As relações pedagógicas e burocráticas que entabulamos com estudantes, colegas, técnicos etc. se pautam ou deveriam se pautar pelo objetivo de "trazer à luz a ideia", de esclarecer a realidade, de revelar a potência das ideias como forças produtivas da realidade.

\footnotetext{
2 MARTINS, Evandro Silva. "A etimologia de alguns vocábulos referentes à educação". In: Olhares \& Trilha, Uberlândia, Ano VI, n. 6, p. 31-36, 2005.
} 
Que não seja assim parece mais um sintoma do que propriamente um problema. Nós, das universidades e instituto federais, por exemplo, não trabalhamos em Instituições de Educação Superior, mas sim em Instituições de Ensino Superior. Do mesmo modo, não nos reconhecemos como educadores, mas sim como docentes. Por que?

Fazendo a pergunta, retomo o argumento inicial: em boa medida isso tem a ver com as condições históricas em que desenvolvemos nossas atividades cotidianas de leitura, análise, interpretação, escrita, debate, orientação etc.

Um traço fundamental dessas condições é a externalização e redução dos custos de produção, com o fim de aumentar a competitividade das empresas, que tem como contrapartida a internalização subjetiva dos custos de integração no mundo do trabalho, que significa eximir empresas e Estados de toda e qualquer externalidade decorrente de suas atividades. Essa externalização dos custos de produção trouxe consigo profundas transformações no mercado de trabalho, sendo uma das principais o que poderíamos chamar da flexibilização generalizada das relações de trabalho.

Um dos subprodutos mais expressivos desse processo é o que chamarei aqui, imprecisamente, de PJtização, que consiste na transfiguração formal ou informal dos trabalhadores em pessoas jurídicas. Isso vem ocorrendo de par com os processos de automação, terceirização, quarteirização, uberização ou, se preferirmos, com o conjunto de mudanças vinculadas à profunda reestruturação produtiva do capitalismo e a um de seus efeitos mais devastadores para os trabalhadores, o desemprego estrutural.

É também na esteira desses acontecimentos que alteram a estrutura de nosso modo de organizar a produção material e espiritual da existência que expressões como empreendedorismo, empregabilidade e carreira passar a sitiar o cotidiano da educação, dos educadores e educandos. Elas exprimem o modo particular como a acumulação flexível de capital, para usar uma expressão de David Harvey, promove o ajustamento das visões de mundo e condutas indivíduos à dialética da acumulação que combina de modo singular a natureza da intervenção estatal e as estratégias empresariais.

É importante notar que os discursos da empreendedorismo, empregabilidade e carreira não se aplicam apenas aos estudantes, mas também a nós mesmos, professores, com efeitos devastadores sobre nossas pretensões coletivas. 
Em qualquer caso somos estimulados a nos pensar como se empresas fossemos, como se o desafio de nossas vidas fosse nos tornarmos rentáveis, como se de nossa valorização no mercado dependesse a realização de nossa existência.

Daí que tornado princípio educativo, o empreendedorismo revele mais dos limites da própria ordem para dar conta de uma série de direitos que pareciam conquistas históricas, do que da revelação de um "capital humano" a ser excitado pela formação educacional.

De fato, a própria ideia de empreendedorismo é uma perversão da formulação original acerca do "empreendedor", conforme Schumpeter. Este, ao desempenhar a "função inovadora" desafiava a ordem do capitalismo liberal, competitivo. Aquele é estimulado a inovar - em incubadoras, empresas júnior e start ups - com o objetivo de se adaptar à ordem do capitalismo neoliberal.

Em boa medida, assim também opera a noção de empregabilidade, na medida em que converte a possibilidade de que um indivíduo tenha sua força de trabalho remunerada numa relação de trabalho relativamente estável com uma empresa algo que compete, quase que exclusivamente, a ele.

Não é à toa que surgiu no Brasil e no mundo algo que poderíamos chamar de "indústria da empregabilidade". Um setor econômico envolvendo revistas, livros, seminários, consultores, programas de rádio e TV, sites, cursos, coachs etc., nos quais se trata de net-working, investimento em si mesmo, etiqueta laboral, zona de conforto, inteligências múltiplas etc. Trata-se de um enorme esforço de pensar os indivíduos como empresas e de fazê-los nos pensar a nós mesmos assim.

É importante não perder de vista, porém, em as condições históricas em que isso se dá, aquelas para as quais as noções de empreendedorismo e empregabilidade procuram ser respostas, simultaneamente, compreensivas e adaptativas.

São situações de uma crise que se aprofunda ao longo do tempo. Ela se iniciou na década de 1970 do século passado e teve um de seus capítulos mais dramáticos no ano de 2008. Suas causas têm a ver com o modo como os constrangimentos econômicos e políticos à acumulação de capital em escala mundial foram superadas. Isto é, tem a ver com a financeirização da economia, com a reestruturação produtiva e a contrarreforma do Estado. 
Para sintetizar o argumento, eu diria que o aumento do uso de tecnologia nas indústrias e a articulação de seus processos produtivos em escala mundial foram possibilidades criadas pela desregulamentação de leis de proteção ao trabalho e ao "capital nacional", gerando as condições necessárias para o fluxo de capitais pelo mundo, que se dá na forma de novos investimentos ou especulação. Em conjunto, isso levou ao processo de desindustrialização, de predomínio do setor terciário como aquele que mais demanda força de trabalho e de precarização das condições de trabalho.

Tentemos como os jovens que vivem no Brasil experimentam essa realidade. Em 2018, $32 \%$ dos desempregados são jovens entre 18 e 24 anos. Isto é, cerca de quatro milhões de jovens aptos a trabalhar não conseguem empregar sua força produtivamente. Entre as pessoas de 25 a 39 anos o desemprego atinge 34,6\% dos indivíduos ou cerca de quatro milhões e quinhentas mil pessoas.

Dados do INEP para o ano de 2016 indicam que a idade média de ingresso na educação presencial é de 24,6 anos e a dos concluintes é de 28,1 anos. Quando se consideram os dados para o ensino à distância esses valores oscilam, respectivamente, para 31,3 e 35,7 anos.

Aprofundando ainda mais a observação das estatísticas de desemprego, o IPEA indica que ele tem um perfil: é da mulher de 18 a 24 anos que vive nas regiões metropolitanas e tem o ensino fundamental incompleto.

Não obstante, ainda que a posse de título superior minimize os riscos de desemprego, dados do Sindicato das Mantenedoras de Ensino Superior para o ano de 2017 indicavam que 1/3 dos formados encontrava-se desempregado. Isto é, nas condições atuais do mercado de trabalho, um diploma universitário não é garantia de emprego.

É nesse contexto de instabilidade e insegurança institucional em relação às condições básicas da existência que a carreira, mais que a profissão, se torna o centro nervoso da atenção do jovem trabalhador. Ele precisa estar preparado para mudar, para ser flexível, desenvolver múltiplas competências, ser capaz de se ajustar a situações as mais variadas, adiar planos de casamento ou maternidade/paternidade, aprender a aprender.

Estamos, de fato, diante de uma ampla e profunda restruturação do mundo do trabalho que, dentre outras coisas, implica a liquidação de profissões ou de áreas delas, e, em certo sentido, da liquidação da própria ideia de profissão e sua substituição pela 
"carreira". Na verdade, trata-se do avanço da flexibilização das condições individuais, cognitivas e psicológicas, demandas pelas possibilidades de ingresso no mundo do trabalho formal.

A "profissão" contemporânea implica a capacidade de adaptar-se à concorrência no mercado para ter as competências e habilidades individuais demandada por empresas ou para com elas empreender lucrativamente. De qualquer modo, parecemos todos, em alguma medida, imagens trêmulas da humanidade.

Isso se revela, em boa medida, na importância que temas como assédio, adoecimento, suicídio, burn-out, depressão etc. adquiriram nas preocupações de quem estuda o "mundo do trabalho".

Isso significa dizer que há uma enorme pressão sobre o sistema educacional. Uma pressão que tem a ver, fundamentalmente, com o aceno de que com mais anos de escolarização aumentam as possibilidades de mobilidade social ascendente.

A situação é de tamanha gravidade que Ricardo Antunes, em seu mais recente livro, fala do "privilégio da servidão". Autores como Ruy Braga, analisando o resultado da precarização das relações de trabalho fala no surgimento do "precariado".

A título de conclusão, gostaria de dizer que creio haver três vetores fundamentais de mudança que atingem diretamente o mundo do trabalho dos educadores. São eles o econômico, o político e o tecnológico. Mas todos estão sintetizados no que eu chamaria de uma "nova cultura educacional", algo que se vincula a um conjunto de valores que tendem a conquistar o espírito de professores e de alunos, e que tem no empreendedor sua figura emblemática.

A mudança econômica fundamental tem a ver com a comodificação da educação, isto é, com a transformação da educação em um bem passível de ser vendido e comprado no mercado, isto é, num serviço que pode ser prestado por empresas privadas que a produzem e adquirido por consumidores que dela necessitam.

Por que esse processo avança? Por duas razões principais: primeiro, pela política de precarização da educação pública e pela consequente criação, de um lado, de um mercado consumidor potencial para essa "mercadoria" e, de outro, de oportunidades de investimento no setor. A educação deixa de ser um direito e se converte numa coisa que só se pode comprar. 
Mas essa conversão implicado direito em coisa implica decisões políticas. Daí que ela dependa de alterações nos dispositivos legais que impõem restrições ao "empreendimento econômico educacional".

Essas mudanças também reverberaram sobre nossos modos de agir politicamente. Das perspectivas universalistas de projetos de sociedade e educação, passamos as políticas identitárias de sociedade e educação. Não fomos capazes, pelo menos ainda, de integrar as questões identitárias relativas ao modo como nossas diferentes condições de ser e estar no mundo são, por assim dizer, dinamizadas pelos processos de exploração e dominação.

Vivemos em sociedades capitalistas. Daí o desafio de situar como, nessa sociedade, as diferenças se tornam ingredientes, conteúdos, da exploração e da dominação.

É também característica específica dessa sociedade o culto à velocidade e às quantidades. Tudo nasce com prazo de validade, com obsolescência programada, com data para perecer, com vida útil mais ou menos breve, com solidez duvidosa. Tudo tende a se liquefazer ou esfumar.

Mas tudo precisa ser registrado quantitativamente, em planilhas e indicadores. O que não pode ser reduzido a números - uma vida, por exemplo - não cabe na métrica de nossa sociedade. De Marx a Baumann, passando por Simmel e Schumpeter, há o reconhecimento de que o espirito de nossa sociedade é atentado pela alienação, pela burocratização, pela atitude blasé e pela destruição, mesmo que criadora.

Para nós, educadores, o problema que se coloca é: como educar pessoas para esse mundo? É desejável, ou mesmo possível sem graves consequências, ajustar-nos à "ética" da concorrência desmedida? Transferindo para cada indivíduo a responsabilidade exclusiva por seu "sucesso" ou "fracasso" resolvemos ou contribuímos para agravar problemas? Aliás, o que são o sucesso e o fracasso?

Enfim, há um conjunto de reflexões de cunho político-existencial que decorre do exercício mesmo do papel de educador. Tentei desenvolver algumas delas aqui, com a limitação de alguém que não domina nem as teorias pedagógicas, mas que se inquieta com o modo como levamos, guiamos, orientamos nossas relações pedagógicas e os princípios que subjazem a elas. 